\title{
SUPPRESSION EFFECTIVENESS OF AEROSOLS: THE EFFECT OF SIZE AND FLAME TYPE
}

\author{
James W. Fleming, Bradley A. Williams and Ronald S. Sheinson \\ Navy Technology Center for Safety and Survivability \\ Combustion Dynamics Section, Code 6185 \\ NAVAL RESEARCH LABORATORY \\ Washington, DC 20375-5342 USA \\ fleming@code6185.nrl.navy.mil phone: 202-767-2065, fax: 202-767-1716 \\ brad@ code6185.nrl.navy.mil: 202-767-3583, fax 202-767-1716 \\ sheinson@code6185.nrl.navy.mil phone: 202-404-8101, fax: 202-767-1716
}

\section{INTRODUCTION}

This paper summarizes efforts to identify properties of aerosols (liquids and solids) leading to effective fire suppression. It is part of the US Department of Defense's Next Generation Fire Suppression Technology Program (NGP) supported by the DoD Strategic Environmental Research and Development Program (SERDP) for identifying suitable replacements for Halon 1301. The number of gas-phase compounds that meet the now stringent list of requirements for suitable replacements is not very large, but there are several condensed phase compounds that offer good fire protection including water and alkali and transition metal compounds. However efficient implementation of liquid or powder aerosol systems is hampered by the lack of a suitable technical database on their fire suppression behavior. Although it is known that size is an important parameter in suppression effectiveness, a quantitative understanding as to the exact role size plays is lacking. Because of this, separating any possible chemical effects from the physical effects which are almost always present is difficult. This project was undertaken to address the lack of quantitative information on aerosol suppression behavior, particularly targeting the effects of size and physical and chemical properties of liquid and powder aerosols. Although the original goals of this project as part of the NGP were specifically targeted for military platforms, the findings are applicable to fire suppression by aerosols in general.

\section{EXPERIMENTAL}

\section{FLAME CONFIGURATIONS}

Experiments to determine the inhibition effect of aerosols on the burning velocity of premixed flames were carried out in Bunsen flames shown schematically in Fig 1a. Burning velocities were determined by the total area method; video images of the flame were recorded to determine the burning surface area. The presence of the aerosol reduces the flame burning velocity, which is manifest as a larger flame surface for a fixed fuel/air flow. Burning velocities for the inhibited flame are compared to the uninhibited flame, thereby minimizing systematic errors in determining an absolute value for the burning velocity. 
Experiments were also conducted to quantify the flame extinguishing effect of aerosols on nonpremixed counterflow flames. A counterflow flame, shown schematically in Fig $1 \mathrm{~b}$, can be characterized in terms of a strain rate, the maximum velocity gradient on the oxidizer side of the flame. Extinction is achieved when the air and fuel flow rates are such that the velocity gradient exceeds a critical value referred to as the extinction strain rate. Suppression agents lower this critical value. Experimental strain rates were evaluated using Laser-Doppler Velocimetry (LDV).

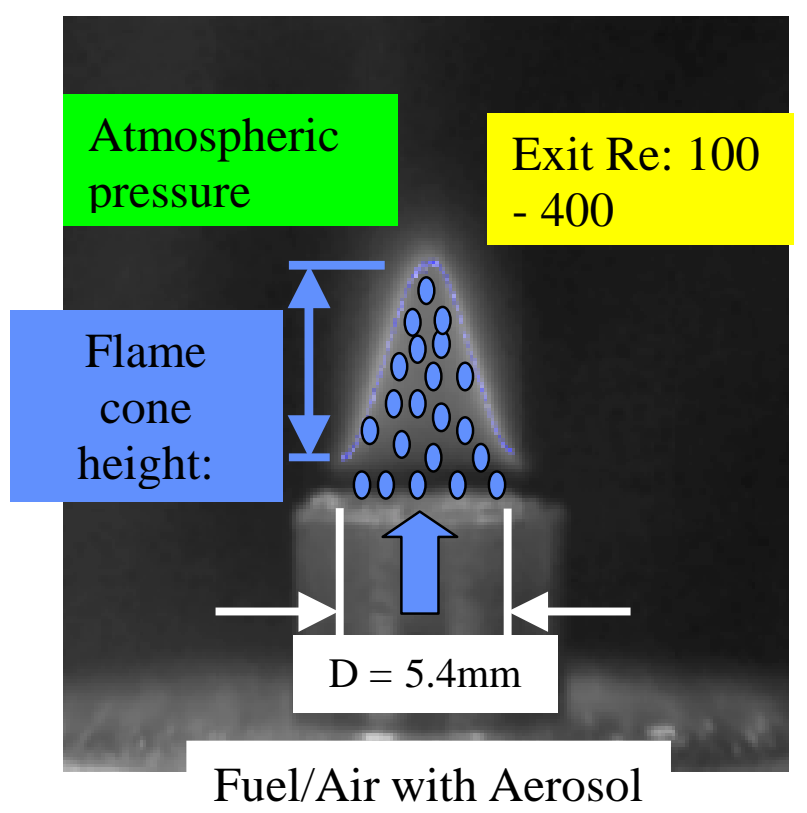

(a)

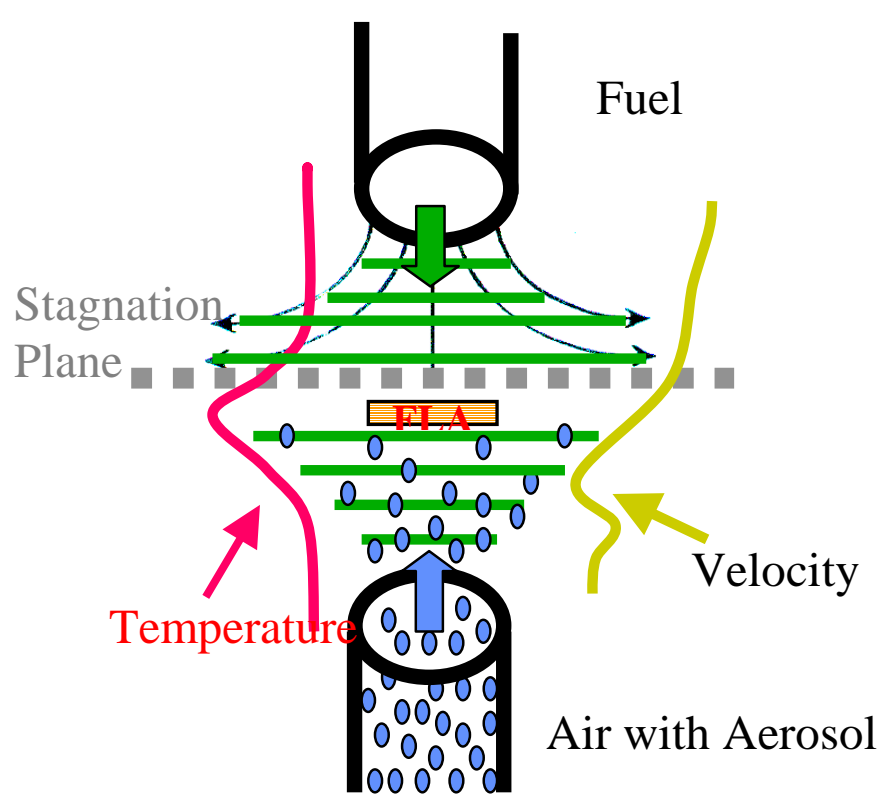

(b)

Figure 1. (a) Picture of flame depicting aerosol addition for determining inhibition effects on premixed burning velocity. (b) Diagram of counterflow non-premixed flame configuration indicating temperature and velocity field as well as addition of aerosol in the air stream. Liquid aerosols were added with the air stream from the bottom tube. Powder aerosols were added with the air stream from the top tube (with fuel in the bottom tube).

\section{AEROSOL GENERATION}

Powder aerosols were created by first sieving prepared powder samples into separate discrete size bins. Powders were delivered to the air stream though a tapered glass tube with a matching tapered brass rod to vary the opening size. This assembly was in contact with a variable frequency, rotating notched-wheel to control the powder delivery rate and maintain powder flow. A modulated helium-neon laser beam with lock-in detection was used to monitor the powder flow delivered to the flame. The powder scattering signal intensity was calibrated to the powder mass flow for each air stream flow rate by weighing the powder exiting the burner tube. 
Two methods were employed to generate liquid aerosols depending on the drop size desired. Very small drops $(<1 \mu \mathrm{m}$ diameter) were generated using a venturi-based nebulizer (TSI Model 3076). A schematic of the nebulizer is shown in Fig 2a. To generate the submicron aerosol, a pressurized air stream flowed through a small orifice, producing a high velocity jet. The resulting pressure drop drew liquid from a reservoir through a small tube and entrained it in the air jet, breaking the liquid into drops. Larger drops impacted against the nebulizer wall and returned to the reservoir. Drops small enough to remain entrained in the air flow were carried from the atomizer. The atomizer was calibrated by measuring the change in mass of the liquid reservoir with time for a fixed air flow rate.

Aerosols composed of larger drops (mean diameters $>\sim 15 \mu \mathrm{m}$ ) were generated using a vibrating orifice aerosol generator (TSI Inc. Model 3450). A schematic of the drop generator is shown in Fig $2 \mathrm{~b}$. Liquid is forced through a pinhole that is acoustically excited by a piezoelectric ceramic. At specific resonant frequencies, the liquid jet breaks up into a stream of monodisperse drops. Drop size depends on the pinhole diameter, the liquid flow rate, the forcing frequency, and the liquid properties. A dispersion cap was used to distribute the drop stream into a mist, sacrificing some of the monodispersity. The mist drop size, velocity, and number density were measured using a phase Doppler particle anemometer (PDPA-Dantec Measurement Technology).

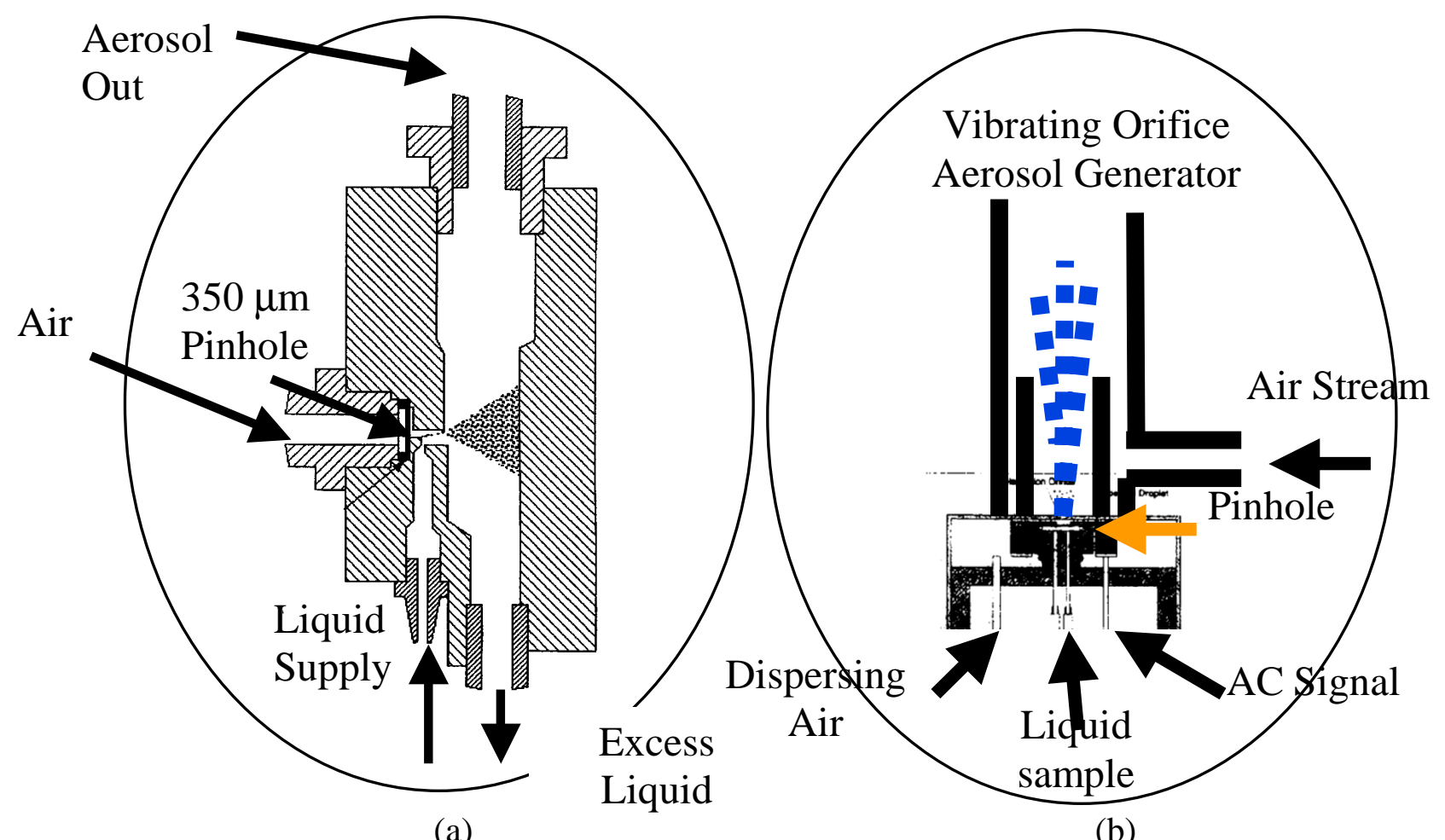

(a)

(b)

Figure 2. Liquid aerosol generation methods for laboratory flame suppression studies: (a) nebulizer for generating sub-micron diameter drops which required $>\sim 1$ SLPM air flow to produce the aerosol (TSI Inc., Model 3076); (b) vibrating orifice aerosol generator (VOAG, TSI Inc., Model 3450). A dispersing air flow, > 1 SLPM was required to spatially separate the drop stream into an aerosol. 


\section{RESULTS}

\section{AEROSOLS OF PHYSICAL SUPPRESSANTS: WATER}

The inhibition effect of sub-micron diameter water drops on the normalized burning velocity of a methane/air flame is plotted in Fig 3a [1]. Also shown are the inhibition effect of $\mathrm{N}_{2}, \mathrm{CF}_{4}$, and $\mathrm{CF}_{3} \mathrm{Br}$. The $\mathrm{CF}_{3} \mathrm{Br}$ data are modeling results considering full chemistry [2,3]. As can be seen in the figure, on a mass basis, the inhibition effectiveness of water mist is comparable to that of $\mathrm{CF}_{3} \mathrm{Br}$. Examination of the thermodynamic properties of $\mathrm{N}_{2}$ and $\mathrm{CF}_{4}$ predict that they should exhibit similar inhibition characteristics on a mass basis. Water is predicted to be 3.5 times more effective than $\mathrm{N}_{2}$ or $\mathrm{CF}_{4}$, which is consistent with the experimental observation. Calculation of the sensible enthalpy ( 300 to $1600 \mathrm{~K}$ ) for the mass of inhibitor which causes a $20 \%$ burning velocity reduction per mole $\mathrm{O}_{2}$ shows that the value for water obtained for the nominal $0.35 \mu \mathrm{m}$ drops in this study lies between that for $\mathrm{N}_{2}$ and $\mathrm{CF}_{4}$, consistent with a physical suppression mechanism [4]. The amount required for $\mathrm{CF}_{3} \mathrm{Br}$ is only $\sim 1 / 4$ of this value. The significantly lower $\mathrm{CF}_{3} \mathrm{Br}$ sensible enthalpy per mole $\mathrm{O}_{2}$ is an indication of a significant chemical inhibition component. Despite the chemical effect for $\mathrm{CF}_{3} \mathrm{Br}$, water aerosols exhibit a comparable effectiveness on a mass basis for small drop size.

The inhibition effect of water aerosols on premixed flames has been modeled using a multiphase combustion model with full chemistry [5]. The results for water vapor and water aerosols of various sizes are shown in Fig 3b [1]. The experimental results for micron aerosols are in excellent agreement with the model, requiring no adjustable parameters. As seen in Fig 3b, water vapor is less effective than water aerosols of drop sizes less than $\sim 15 \mu \mathrm{m}$. The mass of water predicted to produce a $20 \%$ reduction in burning velocity versus drop size is plotted in Fig 3c. There is an increase in effectiveness at small drop size to a limit around $10 \mu \mathrm{m}$. This limiting drop size correlates in the model with complete evaporation of the drops in this flow field. Light scattering evidence from a laser sheet for the submicron inhibited flame confirms the complete evaporation of the submicron mist [1]. Experimental drop size measurements using PDPA for aerosols as they progress through the premixed Bunsen flame are shown in Fig 4. Aerosol drops $\geq 28 \mu \mathrm{m}$ diameter survive travel through this flame (peak temperature $\sim 2100 \mathrm{~K}$ ). The slight size increase for the $28 \mu \mathrm{m}$ mist near the maximum temperature can be attributed to finite spread in the drop size distribution. The slightly larger drops survive longer than the somewhat smaller drops and skew the average to a higher value. Drops from a nebulizer generated mist (average diameter $6 \mu \mathrm{m}$ and $\mathrm{D}_{\mathrm{v}=0.9}<10 \mu \mathrm{m}$, not shown in the figure) completely disappear at the flame front. Thus the experimental evidence is consistent with the predicted $10 \mu \mathrm{m}$ limiting drop size to accomplish complete evaporation in this flame. The multi-phase suppression model also predicts a marked non-linear behavior versus added aerosol mass for drops $>\sim 30 \mu \mathrm{m}$ [5]. This prediction says that experimentally there should be an abrupt extinguishment of the flame near a 50\% reduction in burning velocity for the aerosol-laden flames. Experiments to correlate the observed evaporation behavior with suppression effectiveness of each of these aerosols are pending. 
(a)

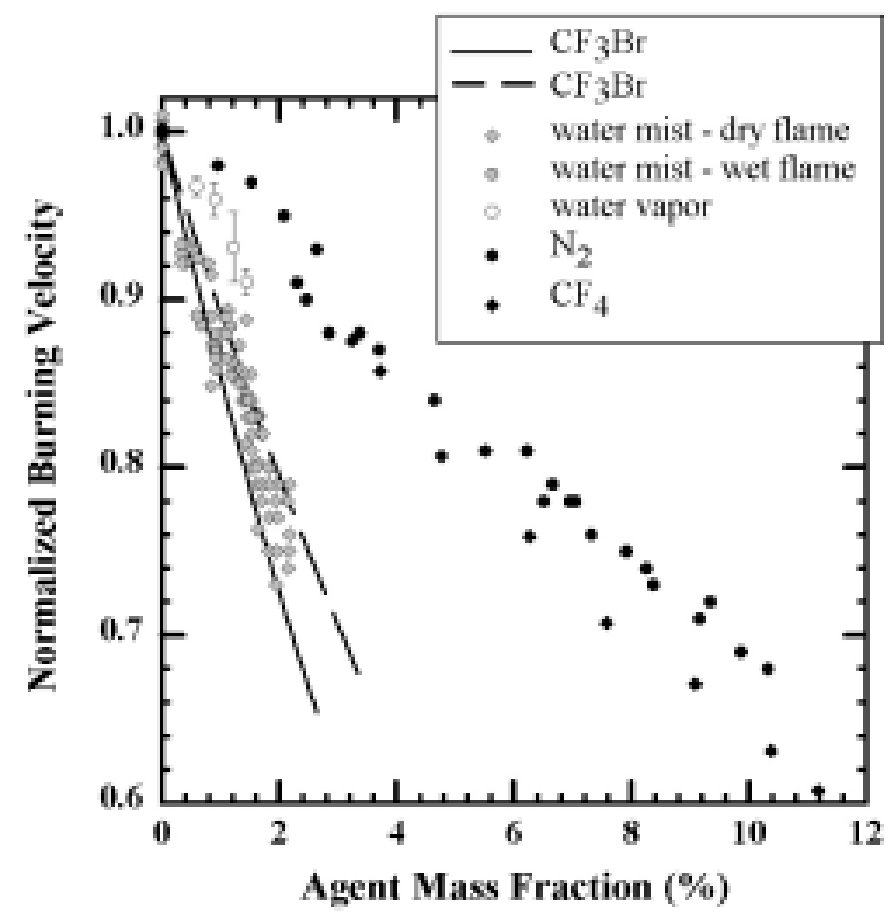

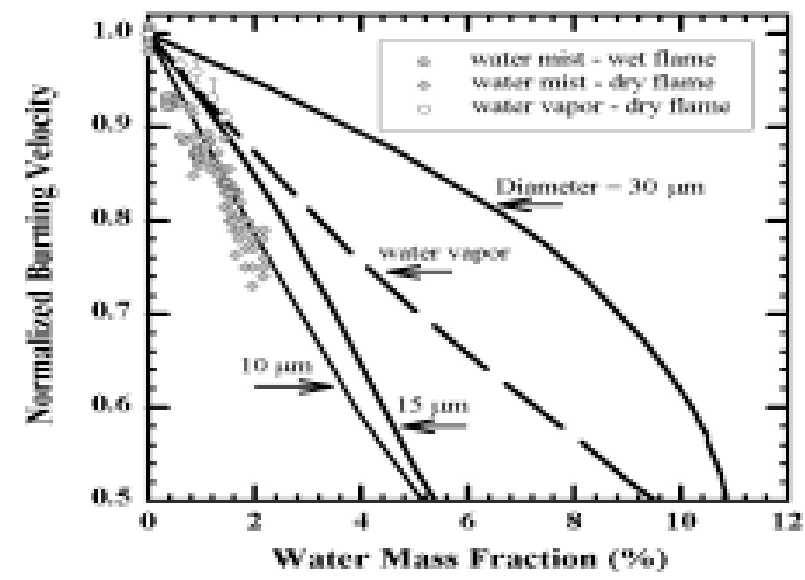

(b)

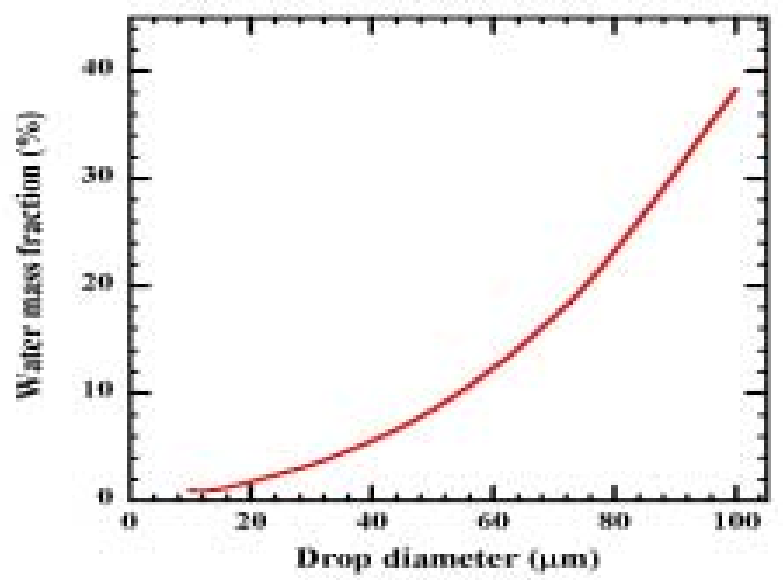

(c)

Figure 3. (a) Normalized burning velocity reduction of premixed methane-air flames by sub-micron diameter water aerosol (gray symbols for dry and humidified flames) and water vapor (open symbols) versus mass of added water [Ref 1]. Solid symbols are for $\mathrm{N}_{2}$ and $\mathrm{CF}_{4}$. Lines are modeling results for $\mathrm{CF}_{3} \mathrm{Br}$ [dashed line, Ref 2; solid line Ref 3]. (b) Experimental data and results of a multi-phase flame model for flames inhibited with the indicated water drop sizes (solid lines) and PREMIX results for water vapor (dashed line) [Ref 1]. (c) Predicted water mass fraction versus drop diameter required to reduce the burning velocity by $20 \%$. 


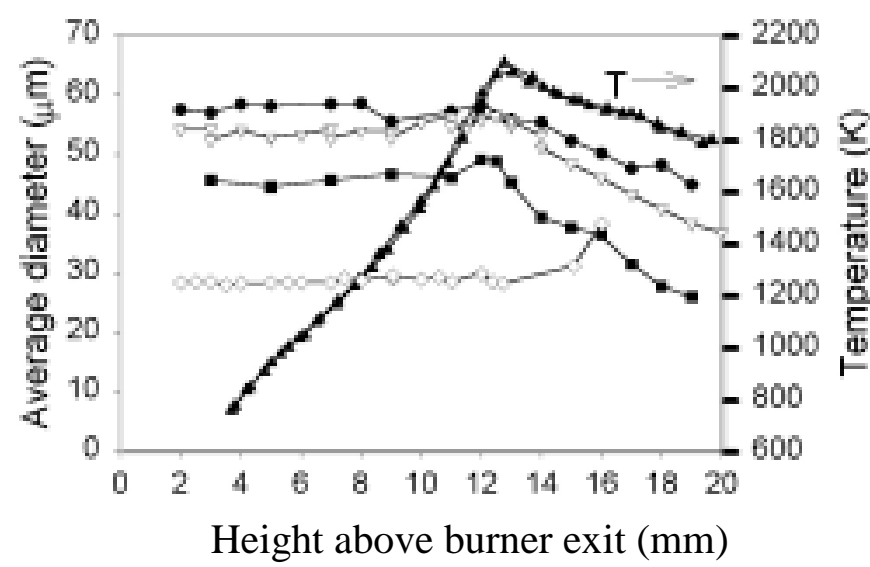

(a)

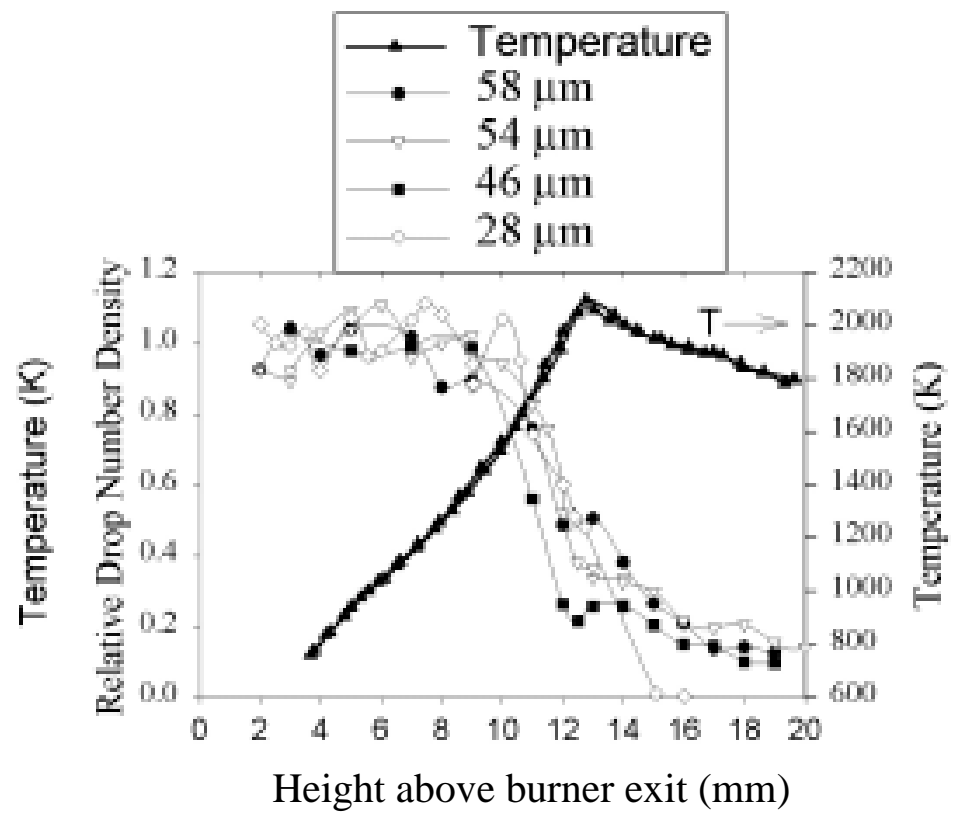

(b)

Figure 4. Water aerosol behavior and temperature in a stoichiometric premixed methane/air Bunsen flame as a function of height above the burner exit: (a) flame temperature and average drop size for four mono-dispersed water aerosols of the indicated drop size.; (b) relative number density and temperature versus position. Temperature was obtained by a coated thermocouple. The relative burning velocity for the aerosol laden flames was $90 \%$ that of the uninhibited flame.

The water aerosol evaporation behavior and aerosol suppression effectiveness have been measured in non-premixed counterflow propane/air and methane/air flames [6]. The water mass required for extinction of various strain rate flames is plotted in Fig 5a. Also plotted is the amount of $\mathrm{CF}_{3} \mathrm{Br}$ required for extinction. As seen in the figure, water aerosols whose drop size is $\leq \sim 40 \mu \mathrm{m}$ are more effective than $\mathrm{CF}_{3} \mathrm{Br}$ on a mass basis. The $14 \mu \mathrm{m}$ drops are $\sim 3$ times more effective. Using PDPA we determined that water drops $<\sim 30 \mu \mathrm{m}$ diameter completely evaporate in the low to high strain rates flames [6]. There is a large increase in effectiveness in going to smaller drop size as seen in Fig 5b. Experimental extinction measurements for $\sim 20 \mu \mathrm{m}$ drops are similar to the results for the $14 \mu \mathrm{m}$ drops, suggesting a limiting drop size for effectiveness between 20 and $30 \mu \mathrm{m}$.

Lentati et al., using a multi-phase flame suppression model they developed, predicted that $20 \mu \mathrm{m}$ is the optimum size for effectiveness of water drops in these flames [7]. Our experimental observations are consistent with this prediction. Using the same model and including a finite distribution for the aerosol, Lazzarini et al. report an underprediction of a factor of two in the suppression effectiveness for a $20 \mu \mathrm{m}$ water mist suppressing a methane/air counterflow flame [8]. The difference could not be attributed to the non-monodisperse size distribution of the experimental mist. Although there appears to be good qualitative agreement in observed and predicted water mist suppression properties in counterflow flames, more work is required on validating the quantitative predictive capabilities. 


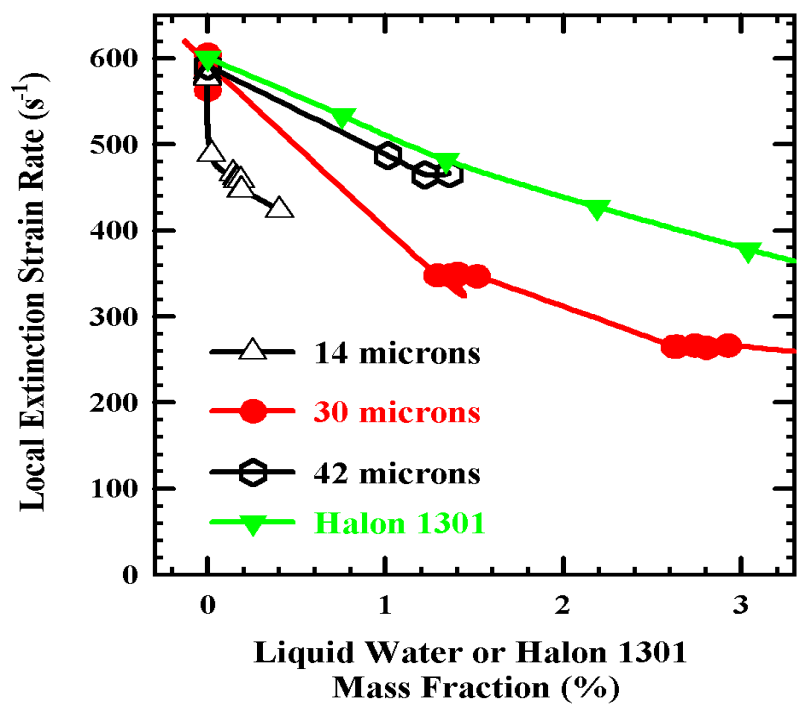

(a)

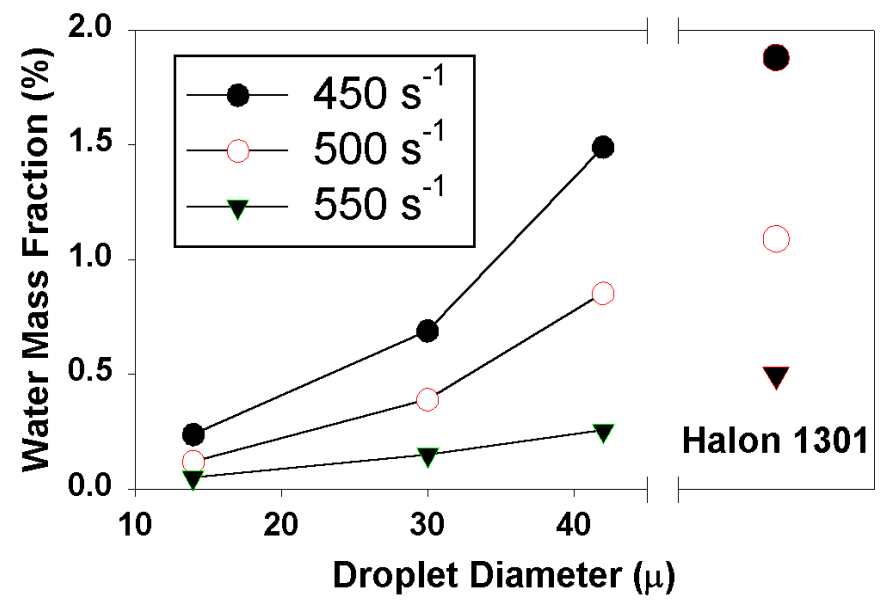

(b)

Figure 5. Extinction of water aerosol inhibited counterflow non-premixed propane-air flames: (a) extinction strain rate as a function of added water aerosol to the air stream for the indicated drop sizes. (b) water mass fraction at extinction as a function of drop diameter for the indicated strain rates.

\section{AEROSOLS OF CHEMICAL SUPPRESSANTS}

The effectiveness of water, a physical agent, has been shown to be 1 to 3 times as effective as $\mathrm{CF}_{3} \mathrm{Br}$, consistent with the maximum sensible enthalpy that this condensed phase agent can provide to the flame though evaporation. Even larger efficiencies have been predicted for other compounds, including the alkali and transition metals [9]. For these compounds, the enhanced effectiveness results from the inhibitor species catalytically removing the $\mathrm{H}, \mathrm{OH}$, and $\mathrm{O}$ flame propagation radicals. These compounds can be one to two orders of magnitude more effective than $\mathrm{CF}_{3} \mathrm{Br}$ at flame inhibition. The majority of these compounds exist as liquids or solids at room temperature and the enhanced suppression potential will not be realized unless the compound evaporates or decomposes by the time it reaches the flame, giving enough time to release the key chemical player(s) in the flame. Because of this, quantitative determination of the suppression effectiveness of these compounds must be deconvoluted from the aerosol size effects of the liquid or powder that is introduced into the flame.

Extinction testing was conducted with both sodium bicarbonate $\left(\mathrm{NaHCO}_{3}\right)$ and potassium bicarbonate $\left(\mathrm{KHCO}_{3}\right)$ [10]. Both powders were mechanically sieved into size ranges of $<38 \mu \mathrm{m}$, 38-45 $\mu \mathrm{m}, 45-53 \mu \mathrm{m}, 53-63 \mu \mathrm{m}$, and 63-75 $\mu \mathrm{m}$. Silica (2\% by mass) was added to the powder samples. Both powders flowed freely with almost no agglomeration noticed. Powder suppression efficiency was evaluated by adding powder to the air stream of non-premixed propane/air and methane/air counterflow flames. Extinction strain rate versus bicarbonate powder mass are presented in Fig 6 a for $\mathrm{NaHCO}_{3}$ and $\mathrm{Fig} 6 \mathrm{~b}$ for $\mathrm{KHCO}_{3}$. Also plotted in Fig $6 \mathrm{~b}$ are the results for $\mathrm{CF}_{3} \mathrm{Br}$. As can be seen in the figure, alkali metal bicarbonate powders are very effective at flame extinction, from 2 to 10 times more effective than $\mathrm{CF}_{3} \mathrm{Br}$. It will be noted from 
the mass scales in Fig 6 that although $\mathrm{K}$ and $\mathrm{Na}$ exhibit similar behavior, $\mathrm{K}$ is $\sim$ twice as effective as Na. Their effectiveness is strongly dependent on size as seen in Fig 6c for K. A $50 \%$ decrease in $\mathrm{KHCO}_{3}$ particle size increases the suppression effectiveness by a factor of 50 . A similar dependence on particle size is also observed for $\mathrm{NaHCO}_{3}$. The effectiveness approaches a limit at small particle size, below $\sim 40 \mu \mathrm{m}$. Hamins [11] measured extinction concentration values for three $\mathrm{NaHCO}_{3}$ aerosols (all $<20 \mu \mathrm{m}$ ) inhibiting several different fuels in a modified cup burner. The cup burner extinction values are in good agreement with our low strain rate counterflow flame extinction values in the limiting particle size region. The effectiveness at small particle size can only be accounted for by a significant chemical contribution to the suppression mechanism $[11,12]$.

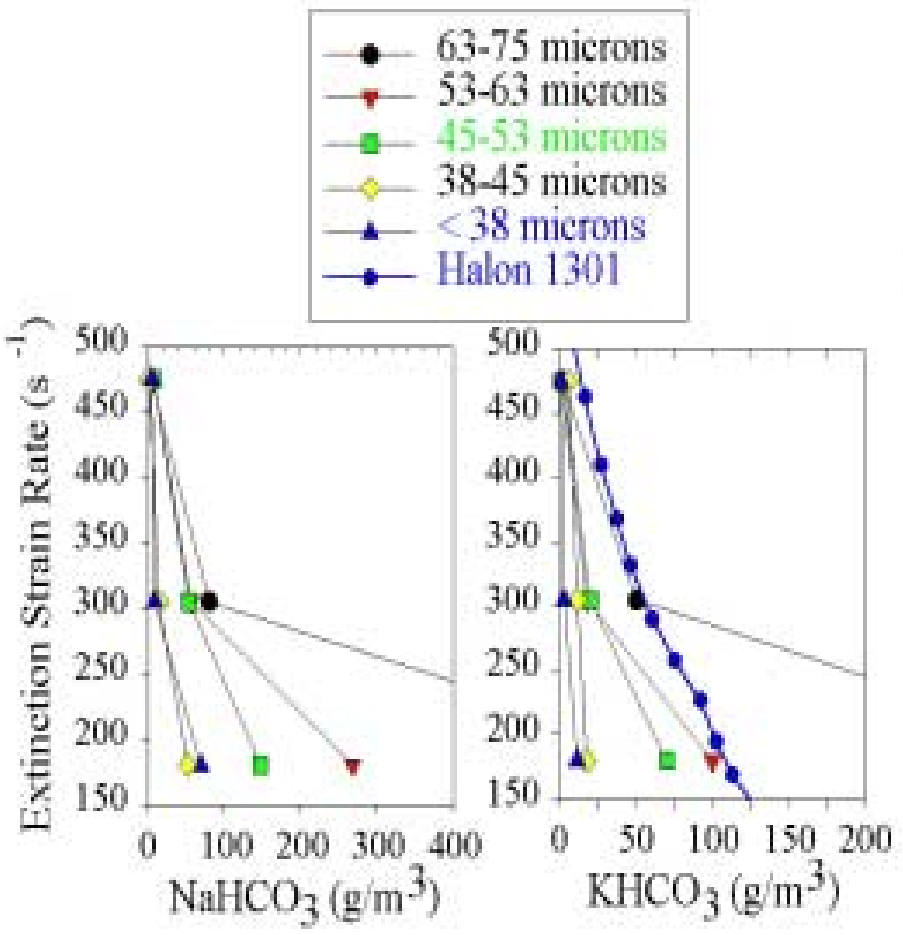

(a)

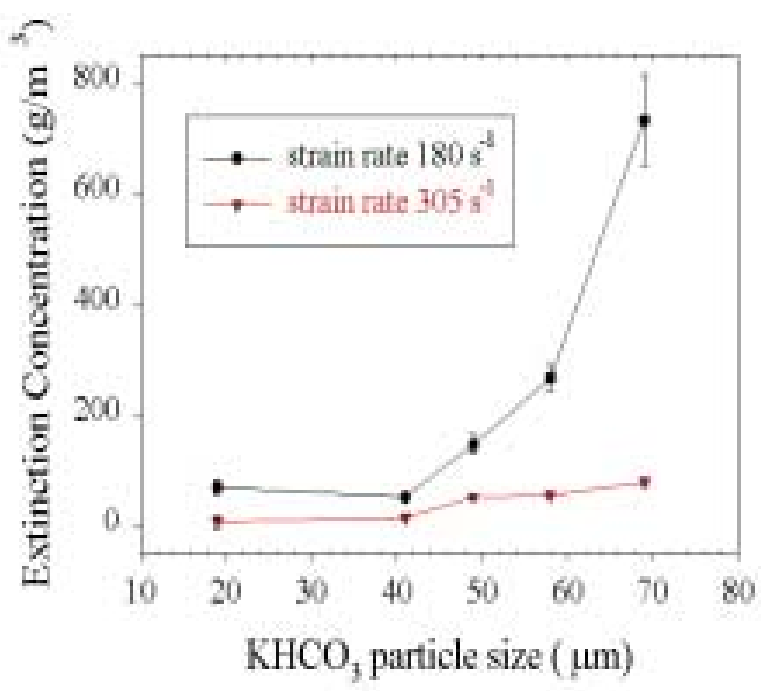

(c)

Figure 6. Extinction of propane-air non-premixed counterflow flames: extinction strain rate versus mass of powder sieved according to the indicated sizes for (a) $\mathrm{NaHCO}_{3}$ and (b) $\mathrm{KHCO}_{3}$. (c) Extinction mass concentration versus particle size for $\mathrm{KHCO}_{3}$ inhibited flames.

\section{DISCUSSION}

Rosser et al. [13] and Mitani and Niioka [14], based on observations for particle suppression behavior in premixed flames, describe the particle suppression mechanism in terms of particle size and residence times. Generalizing these findings to both liquids and solids, four characteristic times relevant to suppression behavior of an aerosol (liquid drop or solid particle) 
can be identified: I. aerosol heating, II. aerosol evaporation (solid or liquid) and/or decomposition (primarily solids), III. generation of the inhibitor radical species in the gas phase, and IV. inhibition of the gas-phase combustion process.

Optimum inhibition efficiency requires the completion of all four steps. The slower steps will determine the extent of inhibition and what aspects of the condensed phased suppression mechanism will contribute to the inhibition process. Times for III and IV involving gas-phase reactions are much shorter than the drop/particle heating times and/or decomposition/evaporation times, I and II. Heating of the aerosol needs to raise the temperature to the aerosol's boiling/decomposition temperature. The heating rate will depend on the thermal conductivity of the aerosol and its surrounding gas as well as the surround gas temperature. Temperatures encountered here are typically $>1800 \mathrm{~K}$ and assuming the aerosols drops/particles are small, the heating time for I is typically short, $<1 \mathrm{~ms}$.

Evaporation of the aerosol requires heating step I to lose mass (vapor) to the surroundings. There are several models that can describe drop evaporation depending on what regimes are relevant and what assumptions need to be made. One model suitable for the conditions under consideration here is [15]

$$
\mathrm{D}^{2}(\mathrm{t})=\mathrm{D}_{0}^{2}-\mathrm{Kt}
$$

where $\mathrm{K}$, the evaporation constant, is given by

$$
\mathrm{K}=8 \lambda /\left(\rho \mathrm{c}_{\mathrm{p}}\right) \ln \left[1+\left(\mathrm{T}-\mathrm{T}_{\text {boil }}\right)\left(\mathrm{c}_{\mathrm{p}} / \mathrm{h}_{\mathrm{vap}}\right)\right]
$$

The time required for complete evaporation is:

$$
\mathrm{t}_{\mathrm{vap}}=\mathrm{D}_{0} / \mathrm{K}
$$

Eqn (1) is referred to as the d-square law for drop evaporation and predicts the drop diameter, D, at any time, $t$, in terms of the original drop diameter, $D_{0}$. The mass transfer is dependent on the temperature, $\mathrm{T}$, and thermal conductivity, $\lambda$, of the surrounding gas as well as on the properties of the drop: heat capacity at constant pressure, $\mathrm{c}_{\mathrm{p}}$; density, $\rho$; enthalpy of evaporation, $\mathrm{h}_{\mathrm{vap}}$; and boiling point, $\mathrm{T}_{\text {boil }}$. According to Eqn (3), the residence time required for the drop to completely evaporate is dependent on the original diameter of the drop. Evaporation times for water as a function of drop size for temperatures ranging form 1100 to $2200 \mathrm{~K}$ are shown in Fig 7 . The evaporation time for a $30 \mu \mathrm{m}$ diameter water drop in an air stream at $2100 \mathrm{~K}$ is seen to be $\sim 2.5$ ms. Evaluation of the evaporation time for particles is more complicated. In the case for the alkali metal bicarbonates, decomposition also occurs. Nonetheless, for these particles the same order of magnitude for the evaporation/decomposition times are predicted. Thus of the four processes that must occur for inhibition by the aerosol, evaporation/decomposition is the time critical process. The time for this process will depend on the residence time of the aerosol in the high temperature environment. 


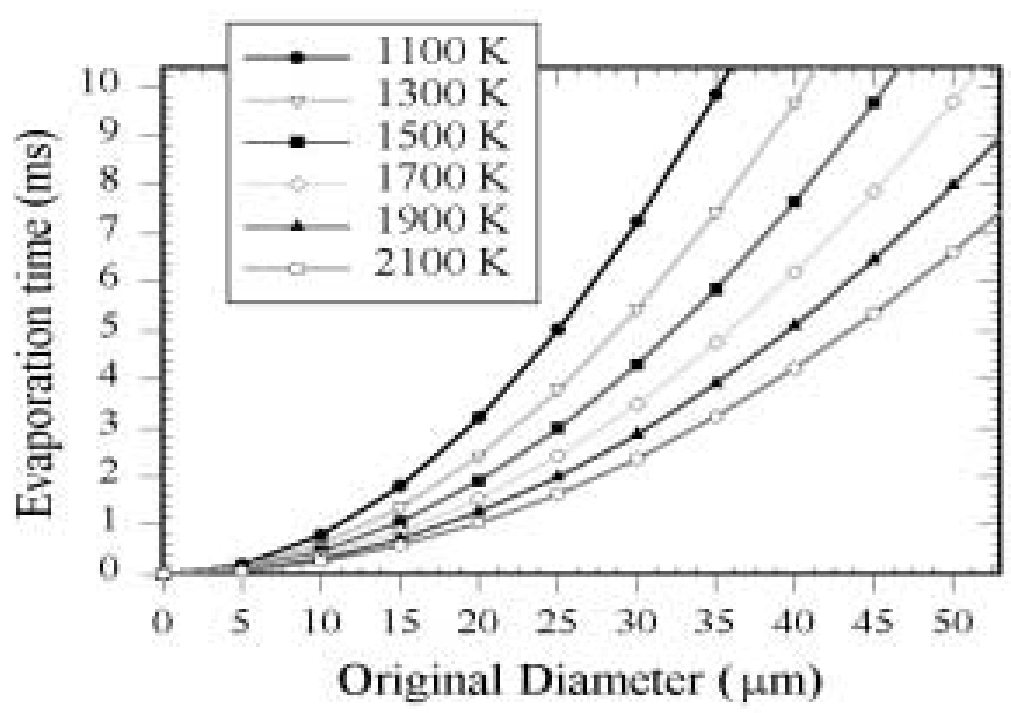

Figure 7. Water drop evaporation time in air at the indicated temperature calculated from Eqn (3). Thermal conductivity data from $\lceil 16\rceil$.

The spatial dependence of the temperature field must be considered in estimating experimental residence times since the aerosol is moving in a non-uniform temperature region as it passes through the flame. This is a problem better suited to the full computation of the flow field. However, it is possible to estimate an upper time limit since the drop/particle begins evaporating at the lower temperature and the resulting smaller drop/particle, in progressing to the higher temperature region, evaporates more rapidly.

Consideration of the flow/temperature field of the methane/air premixed flame suggests that residence times range from 1-2 ms. For the counterflow flames, residence times can be estimated from the inverse of the strain rate. For a strain rate of $400 \mathrm{~s}^{-1}$ (high strain rate for methane, mid strain rate for propane) the residence time is $2.5 \mathrm{~ms}$. The residence time is $10 \mathrm{~ms}$ in a lower strain rate of $100 \mathrm{~s}^{-1}$. For co-flow flames (e.g. cup burner) the residence time is expected to be $\geq 100 \mathrm{~ms}$. These estimates for residence times and the results in Fig 7 for water predict drop size maxima for complete evaporation (and the corresponding onset of drop limiting effectiveness) at $\sim 10 \mu \mathrm{m}$ in premixed flames, $\sim 25 \mu \mathrm{m}$ in high strain rate counterflow flames, and $\sim 45 \mu \mathrm{m}$ for low strain rate flames. These estimates are in agreement with the experimental observations for water aerosols reported here.

The transition diameter from very effective smaller particles/drops to larger, less effective ones depends on the evaporation/decomposition of the aerosol. As can be determined from Eqn (3), evaporation/decomposition times will be shorter for lower boiling/decomposition temperature, specific heat, and enthalpy of vaporization/decomposition. However, these physical properties will result in a less effective thermal agent since they contribute less to raising the overall total system sensible enthalpy. In addition, evaporation times will be shorter at higher flame temperature for a particular solid or liquid. However, a higher flame temperature means a higher burning velocity and shorter residence time. Thus there is a tradeoff between the aerosol's physical properties and its suppression effectiveness, especially for thermal agents. For chemical 
agents, the increased benefit of catalytic participation of the suppressant in the flame chemistry can outweigh the thermal contribution because such small masses are typically required. The interrelated complex dependencies on size, flame condition, and aerosol physical properties can explain why there have sometimes appeared contradictory results in the literature quantifying the effectiveness of condensed phase suppressants.

\section{CONCLUSIONS}

We have investigated the effectiveness of water aerosols and alkali bicarbonate powder aerosols as a function of drop/particle size in both premixed Bunsen flames and non-premixed counterflow flames. The evaporation/decomposition behavior of individual drops/particles correlates with the measured suppression effectiveness in premixed flames (flame burning velocity reduction) as well as in non-premixed flames (extinction strain rate lowering). The residence time of the drop/particle in the high temperature region is key to the suppression performance as it controls the extent of aerosol evaporation. The mass of aerosol required to inhibit the flames decreases with decreasing drop/particle size but reaches a limit, below which there is no further advantage in size reduction. For a particular aerosol, the particle/drop size limit that assures complete vaporization/decomposition provides the maximum suppression effectiveness per mass of added aerosol. This assures that the maximum sensible enthalpy is available due to the endothermic phase change for the physical agents and a maximum concentration of any gas-phase chemical species released for the chemical agents that can participate in the flame radical concentration reduction.

The conclusions made here are useful for providing understanding of the suppression behavior of condensed phase agents. The derivations have not treated the complexity of the flowfield nor the impact of specific chemistries to the overall suppression mechanism. Because residence times will be subject to how well the drop/particle follows the gas streamlines, generalizations become more difficult for quantifying evaporation/decomposition times and their impact on suppression effectiveness. In order to fully explore and predict condensed phase suppression behavior in different flame scenarios for specific compounds, experimentally validated multi-phase flame suppression models are required.

\section{ACKNOWLEDGMENTS}

This research is primarily sponsored by the US Department of Defense's Next Generation Fire Suppression Technology Program funded by the DoD Strategic Environmental Research and Development Program. We also acknowledge the U. S. Naval Sea Systems Command and the Office of Naval Research through the Naval Research Laboratory for partial funding support. We would also like to thank several people who contributed to this project including M. Reed, E. Zegers, P. Fuss, and E. Chen for their experimental efforts and D. Dye for developing the data collection programs. 


\section{REFERENCES}

1. Fuss, S.P., Chen, E.F., Yang, W., Kee, R.J., Williams, W.A, and Fleming, J.W., "Inhibition of Premixed Methane-Air Flames by Water Mist," Proc. Combust. Inst. 29, accepted (2002).

2. Noto, T., Babushok, V., Hamins, A., Tsang, W., "Inhibition Effectiveness of Halogenated Compounds", Combust. Flame 112: 147-160 (1998).

3. Parks, D.J., Alvares, N.J., and Beason, D.G., "Fundamental Flame-Speed Measurements in Combustion Gases Containing $\mathrm{CF}_{3} \mathrm{Br}$," Fire Safety J. 2: 237-242 (1979).

4. Sheinson, R. S., Penner-Hahn, J. E., and Indritz, D., "The Physical and Chemical Action of Fire Suppressants," Fire Safety J., 15, 437-450 (1989).

5. Yang, W. and Kee, R.J., "The Effect of Monodispersed Water Mists on the Structure, Burning Velocity, and Extinction Behavior of Freely Propagating, Stoichiometric, Premixed, MethaneAir Flames," accepted Combust. Flame (2002).

6. Zegers, E.J.P, Williams, B.A., Sheinson, R.S., and Fleming, J.W., "Dynamics and Suppression Effectiveness of Monodisperse Water Droplets in Non-Premixed Counterflow Flames," Proc. Combust. Inst. 28: 2931-2938 (2000).

7. Lentati, A.M. and Chelliah, H.K., "Dynamics of Water Droplets in a Counterflow Field and Their Effect on Flame Extinction," Combust. Flame 115: 158-179 (1998).

8. Lazzarini, A.K., Krauss, R.H., Chelliah, H.K., and Linteris, G.T., "Extinction Conditions of Non-Premixed Flames with Fine Droplets of Water and Water/NaOH Solutions," Proc.

Combust. Inst. 28: 2939-2945 (2000).

9. Babushok, V., and Tsang, W., "Inhibitor Rankings for Alkane Combustion," Combust. Flame 123: 488-506 (2000).

10. Fleming, J.W., Reed, M.D., Zegers, E.J.P., Williams, B.A., and Sheinson, R.S., "Extinction Studies of Propane/Air Counterflow Diffusion Flames: The Effectiveness of Aerosols", Proceedings of the Halon Options Technical Working Conference, 403-414 (1998).

11. Hamins, A., "Flame Extinction by Sodium Bicarbonate Powder in a Cup Burner," Proc. Combust. Instit. 27: 2857-2864 (1998).

12. Williams, B.A. and Fleming, J.W., "CF $3 \mathrm{Br}$ and Other Suppressants: Differences in Effects on Flame Structure," Combust. Inst. 29, accepted (2002).

13. Rosser, W.A., Inami, S.H., and Wise, H., "The Effect of Metal Salts on Premixed Hydrocarbon-Air Flames," Combust. Flame 7: 107-119 (1963).

14. Mitani, T. and Niioka, T., "Extinction Phenomenon of Premixed Flames with Alkali Metal Compounds," Combust. Flame 55:12-21 (1984).

15. Turns. S, An Introduction to Combustion: Concepts and Applications, 1st ed., McGraw Hill, Inc, New York, p. 314 (1996).

16. Kays, W.M. and Crawford, M.E. Convective Heat and Mass Transfer, $2^{\text {nd }}$ ed., McGraw-Hill Book Company, New York, p. 388 (1980). 